\title{
O USO DA HIDROVIA NA LOGÍSTICA URBANA
}

\author{
E. D. R. Rodrigues ${ }^{1}$; O. F. Lima Júnior ${ }^{2}$ \\ 1,2 LALT- Laboratório de Aprendizagem em Logística e Transportes \\ UNICAMP -Universidade Estadual de Campinas, C. Universitária. Zeferino Vaz-Campinas SP \\ esterdivieso@gmail.com ${ }^{1}$, oflimaj@fec.unicamp.com²
}

Resumo: $\mathrm{O}$ transporte hidroviário é o mais econômico e menos poluente entre os modais. Em contrapartida, o transporte de cargas urbanas é um desafio hoje. O uso do transporte hidroviário na movimentação urbana de cargas permite redução de custos, melhoria de serviços e redução de impactos ambientais. Esta soluçáo é uma oportunidade pouco explorada no Brasil. O objetivo deste trabalho é analisar como o transporte hidroviário de cargas pode auxiliar na logística urbana em cidades do Brasil, com base em casos existentes no mundo. Estão sendo estudadas práticas em países onde as hidrovias são utilizadas em áreas urbanas, como, por exemplo, França e Holanda, e em seguida, o potencial de uso do modal em cidades do Brasil em um estudo de caso.

Palavras-chave: Logística urbana, Transporte intermodal, Hidrovia.

\section{Introduçáo}

Os conflitos no espaço urbano mostram a necessidade de explorar novas alternativas para a logística urbana. Algumas iniciativas em cidades europeias demonstram que há um potencial significativo do uso de vias navegáveis urbanas para a distribuição de mercadorias [1]. Uma revisão de experiências na área da logística urbana fluvial é vista em [2] destacando-se as experiências francesas e holandesas. O objetivo dessa pesquisa é analisar como o transporte hidroviário pode atuar na logística urbana em cidades brasileiras, com base em práticas existentes no mundo. Além de ganhos operacionais e de redução de custos, as maiores oportunidades do uso do transporte hidroviário na logística urbana estão relacionadas à redução de impactos ambientais, principalmente na emissão de poluentes e no congestionamento viário. A análise de boas práticas internacionais pode contribuir com a identificação de oportunidades para a utilização do potencial hidroviário brasileiro.

\section{Metodologia}

A metodologia será o estudo de caso [3], conforme o fluxograma da Figura 1, além da aplicaçâo de um grupo focal para desenvolvimento do estudo. 


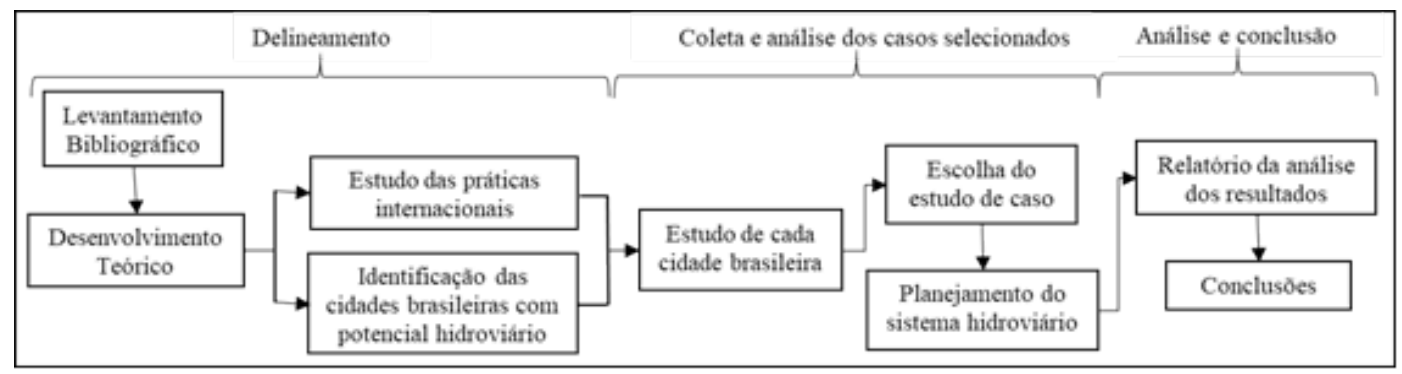

Figura 1 - Fluxograma das etapas do estudo de caso.

\section{Resultados esperados}

A análise comparativa de experiências internacionais permitirá a identificação de boas práticas e oportunidades de uso do transporte hidroviário e o estudo de caso a ser desenvolvido discutirá estas possibilidades adequadas à realidade nacional. Espera-se identificar alternativas para melhorar a logística nas cidades.

\section{Referências}

[1] VAN DUIN, J. H. R.; KORTMANN, L. J.; VAN DE KAMP, E. M. Towards sustainable urban distribution using city canals: the case of Amsterdam. In: The 10th International Conference on City Logistics, 2017, Phuket, Thailand. Institute for City Logistics. p. 44-57, 2017.

[2] JANJEVIC, M.; NDIAYE, A. B. Inland waterways transport for city logistics: a review of experiences the role of local public authorities. In: 20th International Conference on Urban Transport and the Environment, 2014, Southampton. UK. Brebbia, C.A. (Ed.), v. 138, p. 279-292.

[3] YIN, R. K. Estudo de Caso - Planejamento e Métodos. 4. ed., Porto Alegre: Bookman, 212 p, 2010. 